\title{
'Dead Bodies as a Daily Business' - Affective Work Events, Emotions and Emotion Regulation in the Work of Undertakers
}

Jürgen Wegge, Katharina Julia Goerdeler, and Denise Dörfel*

Scientific articles usually go through a peer-review process. This means that independent researchers evaluate the quality of the work, provide suggestions, and speak for or against the publication. Please note that the present article has not (yet) undergone this standard procedure for scientific publications.

\section{Affiliation:}

Faculty of Psychology, Work and Organisational Psychology, Technische Universität Dresden,

Germany

Address:

Prof. Dr. Jürgen Wegge: juergen.wegge@ @tu-dresden.de

Dr. Katharina Julia Goerdeler: katharina.julia.goerdeler@googlemail.com

Dr. Denise Dörfel: denise.doerfel@tu-dresden.de

*Correspondence concerning this article should be addressed to Denise Dörfel, Faculty of Psychology,

TU Dresden, D-01062 Dresden, Germany, Phone: +49 (0)351 463 36688, Fax: +49 (0)351 46333589.

E-mail address: denise.doerfel@tu-dresden.de

Keywords: compassion and sympathy; display rules; job autonomy; job satisfaction; time pressure 


\title{
'Dead Bodies as a Daily Business' - Affective Work Events, Emotions and Emotion Regulation in the Work of Undertakers
}

\author{
Abstract \\ BACKGROUND: Affective Events Theory (AET) postulates that job characteristics have an impact \\ on job attitudes and work behaviour via affective events and reactions. However, the display of \\ positive emotions can be rather problematic in undertakers and be in conflict with displaying \\ compassion.
}

OBJECTIVE: This study examines work events eliciting various emotions in the work of undertakers and how display of emotions in this profession affects job satisfaction. We thereby focus on AET and extend this by investigating time pressure as a moderator of the relationship between autonomy, positive emotions and job satisfaction.

METHODS: First, we collected specific affective work events of undertakers in a pilot interview study. Second, $N=112$ undertakers participated in a cross-sectional survey measuring affective events, emotional display, commitment to display compassion, autonomy, time pressure, job satisfaction and work engagement.

RESULTS: Experiencing positive emotions at work is beneficial even in undertakers. Additionally, autonomy was associated with positive emotions particularly under high time pressure and low commitment to display compassion moderated the link between work events and showing compassion.

CONCLUSIONS: Taken together, undertakers' well-being is associated in complex ways with the interplay of positive emotions, autonomy and time pressure at work and individual differences in commitment for displaying compassion to clients. 


\section{Introduction}

Emotions are responses to internal or external events which are perceived as relevant for individuals. These responses are characterized by a subjective experience, a central and peripheral physiology as well as a specific behaviour (1). Emotions and their regulation constitute an integral part of our work life, influence subjective well-being, attitudes towards work and work behaviour (2-6). As a consequence, a large body of research regarding the causes and consequences of affective experiences at work exists today for different vocational fields (e. g. 7 for nursing, 8 for call centre work, 9 for service workers, 10 for police, 11 for sales employees), and affective events theory (AET, 12) has often been used as a framework for studying causes and consequences of emotions at work (for a review see 4).

AET postulates that job characteristics have an impact on job attitudes (e.g., job satisfaction) and work behaviour (e.g., turnover, helping new colleagues at work, counterproductive work behaviour) via both a direct and an indirect path. In the direct path (the cognitive route) job characteristics function as inputs in conscious judgments related to work, in particular to job satisfaction. The existence of such a path between work features and job satisfaction is well established also in research on job design (e. g., see $13,14,15$ ). The indirect path postulated in AET is linked to the direct experience of emotions at work and was vastly ignored before the formulation of AET. This path works via the affective route. Job characteristics (e.g., job autonomy) determine the occurrence of affective events at work (e.g., an argument with an unfriendly client). These events elicit emotions (e.g., anger), which is moderated and directly influenced by personality dispositions. In turn, these affective reactions influence both job attitudes and affective based work behaviour (see Figure 1) (16-18).

Grandey and Melloy (19) combined AET with the concepts of emotional labour and emotion regulation (Revised Model of Emotional Labour as Emotion Reg-ulation). In their hierarchical, integrative model, the authors describe the relationship of work context (work role interaction expectations such as display rules, work features such as auton-omy), individual differences, 
emotional events, affective reactions and emotion regulation with individual and organizational outcomes (such as dissonance, well-being, health, job satis-faction, or team performance).

- $\quad$ insert Figure 1 about here -

Similar to AET, Grandey and Melloy (19) assume that affective events at work lead to affective reactions. Additionally, the model assumes that these affective reactions trigger emotion regulation, and the association between events and affective reactions/emotion regulation is moderated by work role expectations and individual differences (e. g. personality, abilities). In contrast to AET, the model poses that work features (job autonomy, social climate, managerial practices) moderate the relationship between affective reactions/emotion regulation and proximal outcomes (e.g. emotional disso-nance, affective behaviour) as well as more distal outcomes, such as health and job satisfaction. Since the type and nature of relevant work events is not directly specified in AET, these have not been tested regularly (20). Therefore, the first goal of our study is to contribute to the literature by identifying relevant affective work events. We chose a specific workplace which, to our knowledge, has attracted only a limited amount of research so far (e. g. 21, 22): the work of undertakers who have to deal with clients suffering bereavement. To explore the "emotional landscape" in this profession, we first conducted an exploratory interview study that seeks to identify central events related to the activation of emotions. According to the appraisal framework by Scherer (23), emotions can be categorized into antagonistic, achievement, resignation or approach related via the two dimensions positive - negative and passive/calm - active/aroused. We considered the antagonistic emotions anger and disgust (negative, high arousal) and the achievement emotions joy and pride (positive, high arousal) relevant for the (health) service domain, the resignation emotion sadness (negative, low arousal) and the approach emotions compassion and sympathy (positive, low arousal) prominent in undertakers`work.

Based on insights from this qualitative study, we examine if basic propositions of AET are also valid in the unique service work of undertakers'. More specifically, we analyze if the link between job autonomy and job satisfaction that is considered to be mediated by affective work events and positive emotions is also observable in this context. As will be argued in more detail below, achievement emotions like pride, joy and contentment (23) can be considered inappropriate in this 
setting and, therefore, positive effects of job autonomy could be much weaker for undertakers. In a similar vein, we investigate the impact of individual differences in eliciting specific emotions, an important moderator variable included in AET (see e. g. 24) and in the Revised Model of Emotional Labour as Emotion Regulation (19). Funeral homes specifically portray their client support as being compassionate and sympathetic (22). Thus, the expression of these approach emotions is vital for the business. We therefore examine how individual differences in commitment to showing compassion and sympathy moderates the relationship between related work events and the expression of these emotions.

A third goal of our study is to extend the well-founded platform of AET by focusing on the impact of work features in the immediate process of emotion regulation that occur after the development of a specific emotion. More specifically, we propose that features of work such as having high time pressure because of demanding customers not only influence the existence and probability of affective events at work, but also directly impact the success of immediate regulation of emotions at work (e.g., if positive emotions are shown). There are findings of interactive effects between quantitative demands (e. g. time pressure) and emotional demands (e. g. 'difficult' customers) on health (emotional exhaustion, absenteeism) and work related outcomes (turnover intentions, work engagement) (25-28). However, these interactions have not been investigated with regard to the temporal dynamics between work features, affective work events and affective reactions. Therefore, it is our goal to show empirically that work features have to be considered again after emotions already have been elicited at work. This is also in line with the Revised Emotional Labour as Emotion Regulation Model (19), which postulates that work features moderate the association of affective reactions and their regulation with job satisfaction. Figure 1 illustrates how an extended AET integrating this overlooked aspect of work features should look like. In what follows, we first present results of our pilot study. Next, we review the foundations of the specific hypotheses examined in the main study. 


\section{Theoretical Background and Hypotheses}

\subsection{Pilot study: Work events eliciting different emotions in the work of undertakers}

Based on Weiss and Cropanzano (12), affective work events are defined as "proximal causes of affective reactions", and they are "things happen to people in work settings and people often react emotionally to these events". Given these definitions, a clear specification of which kinds of affective work events elicit which emotion or affective state does apparently not exist within AET. Although, Ohly and Schmitt (18) offered a taxonomy based on the available literature, to the best of our knowledge, we do not know empirical research on affective work events that occur in the work of undertakers. For the purpose of our main study, we therefore conducted an explorative pilot study in which we carried out seven standardized interviews with undertakers from different funeral homes to identify possible, detailed work events that are related to emotions in the work of this profession. Prior to the interviews, we told the interviewed persons about our main study's purpose. The interviews were conducted with both owners of rather small family businesses and owners of large undertakers' companies, all being based in Berlin, Germany. The length of interviews varied between 20 minutes and one hour, depending on the detailed descriptions of examples given by the interviewed person while answering our questions.

Following the principles of the critical-incident technique (present-oriented approach) (29), we asked these undertakers to recall events and situations at their actual workplace in which specific emotions were triggered. Questions of these interviews were, for example: "Could you please recall a situation / an event at this workplace in which you felt proud afterwards?" To get insights of undertakers' work, we repeated the questions in the same way for other basic human emotions. We choose to ask for central events related to the activation of pride, joy, contentment, anger, disgust, sadness, compassion and sympathy (23). The identified work events and their related emotions are presented in Table 1. 
With regard to our main study, we then formulated corresponding items for our new questionnaire focusing only on those events that were considered to be related to positive emotions (pride, joy, contentment) as well as to compassion and sympathy (see Table 2 and below for more details).

- $\quad$ insert Table 2 about here -

\subsection{Job autonomy, job satisfaction, positive work events and the display of positive emotions}

The affective route of AET states that work characteristics influence job attitudes (e.g., job satisfaction) mediated by the occurrence of specific work events that, in turn, influence the occurrence of emotions (see Figure 1). In examining this route, we refer to one of the core motivational job features, job autonomy that is defined as "the degree to which the job provides substantial freedom, independence, and discretion to the employee in scheduling the work and in determining the procedures $[\ldots]$ " (30, p. 162). Thus, undertakers perceiving high levels of job autonomy should experience an enriched work environment that should enable them to create and organize their working day more independently: High levels of job autonomy should enable them to decide and choose their working tasks and procedures on their own. In these motivating conditions, the intrinsic selection of work situations that are successfully managed and are therefore related to positive work events (e.g., pleasant social interactions, recognition) will happen more often (see also 6). Therefore, high levels of job autonomy provide more opportunities for positive work events to occur and positive work events drive the experience and expression of positive (high and low arousing) emotions like joy, pride, and contentment $(16-19,23,31)$. Furthermore, AET states that positive emotions are linked to job satisfaction. One explanation for this link can be derived from broaden-and-build theory, which predicts that positive emotions build resources that foster success and positive job attitudes at work (32). This idea was also supported in large scale studies examining basic assumptions of AET. Based on data from 2,091 call centre representatives working in 85 call centres in the UK, a study (8) found that job autonomy fosters the occurrence of positive emotions at work and that experiencing positive emotions contributes to unique variance in job satisfaction (see also 7, 16). 
However, undertakers are typically expected to hide or suppress positive emotions, in particular in client interactions in order to show consideration for their feelings. To give an example, joy, pride, and contentment about the fact that a new client buys an expensive funeral after a successful counselling conversation should be hided since this 'purchase' is associated with a loss on the part of the client. Likewise, positive emotions about 'selling' a second funeral to a client who has only recently been a client of the undertaker should not be displayed as well, as seeing the client again implies that the client repeatedly suffers bereavement. Therefore, otherwise positive work events can be rather problematic in this context. Nevertheless, it can also be argued that positive emotions and their immediate consequences for attention and well-being should be present even in this situation. If positive emotions are experienced, this will automatically lead to a rise of attention or interest in the employee, at least for a short time. Additionally, expressing the positive emotion could be postponed to later, to situations where only colleagues are present. Thus, even if the prescribed work role requires the suppression of positive emotions in interactions with clients, the valued effects of positive emotions could be observable (see 33, p. 601-602, for a similar argumentation based on findings from emotional psychology). Taken together, the relationship between job autonomy and job satisfaction should be partly mediated by both the occurrence of positive work events and the display of positive emotions in the service work of undertakers, as well. Thus, our first set of hypotheses is:

H1: In the work context of undertakers, job autonomy is (a) positively related to job satisfaction and this link is (b) mediated by both positive work events and the display of positive emotions (e.g., pride, joy, and contentment) at work.

\subsection{Time pressure as potential moderator between job autonomy, display of positive emotions and job satisfaction}

What is the role of time pressure in experiencing emotions and coping with emotions at work? Time pressure activates energy resources and is positively associated with effort and achievement. However, it is also positively related to strain when employees can't recover from the invested effort, and energy depletion occurs (for a review see 34). With respect to the expression of emotions, Rafaeli and colleagues (35) found that both store busyness and customer demands are related to the expression of positive emotions. To maintain control over customers and to facilitate customer transactions, 
service employees displayed positive emotions less often during busy times. The authors suggest that this is the case because expressing positive emotions will encourage customers to prolong service transactions. Similarly, there are studies showing stress-exacerbating effects if high emotional (e. g. a 'difficult' customer) and high quantitative demands (e. g. time pressure) occur in combination (on emotional exhaustion, stress-related turnover intentions, absenteeism, 25, 26, 27). On the other hand, if customers were very demanding (e.g., requiring complex responses from service employees) positive emotions were shown more often because in this situation this helped the employees to gain control over the service transaction. In this case, time pressure might induce the presentation of (faked) positive emotions in order to achieve task goals better. This is in line with findings that a combination of high emotional and quantitative demands could also lead to positive outcomes in terms of motivational indicators (e.g.. work engagement, meaning in work, 26, 28). Moreover, time pressure has a motivating influence that particularly becomes apparent when high levels of job control exist, which transform stress into energy (36). These results are in line with the Demand-Control Model as well as with the Job Demand-Resources Model, both describe jobs with high demands and high resources (control) as active and motivating $(37,38)$.

Applied to the work context of undertakers, we propose that the positive influence of job autonomy on the display of positive emotions should be enhanced by high levels of time pressure. Time pressure lets the person focus on the core tasks (e. g., positive client interactions, see also 39). In this way, it should also provide energy to capitalize on the inherent potential of high levels of job autonomy (e.g., flexibility to adapt work tasks and procedures). Accordingly, time pressure should enhance the likelihood of positive emotional states that are linked with autonomy at work (e.g., the display of activating positive emotions).

On the other hand, we propose that the display of positive emotions might be particularly beneficial for subjective well-being at work (high levels of job satisfaction) when time pressure is low. In these conditions, the undertakers might experience positive emotions longer (due to the possibility of longer, positive client interactions), and might therefore experience positive emotions in a more genuine way. Whereas under high levels of time pressure, these emotions are probably shorter and might even be more artificial (as in the case of service providers analyzed by 35 ) and might 
consequently be more demanding for undertakers (for more details on surface acting see 40).

Accordingly, our next (moderated-mediation) hypothesis is:

H2: The paths between job autonomy and display of positive emotions, as well as between display of positive emotions and job satisfaction are moderated by time pressure. When time pressure is high, the positive relationship between job autonomy and displaying positive emotions is stronger, whereas the positive relationship between displaying positive emotions and job satisfaction is weaker compared to low levels of time pressure.

\subsection{Compassion eliciting work events, display of compassion and sympathy and work engagement}

Undertakers tend to regard themselves as counsellors and "serve as important listeners" for bereaved families (21, p.277). Accordingly, Bailey (22) noted that compassion and concern are genuinely felt by undertakers. However, as our pilot study showed, the expression of compassion and sympathy is also important for undertakers' business. In this regard, we specify compassion and sympathy as the emotions that are most likely to be felt and displayed by undertakers according to their business goals.

Referring again to the affective route of AET (see Figure 1) and the research above, we proceed from the assumption that compassion eliciting work events (e. g., support during clients' bereavement or personal affection by the client's fate) trigger compassion and sympathy of undertakers. Additionally, we propose that the display of compassion and sympathy are, in turn, positively related to work engagement, an often analysed work outcome which is defined as a persistent state being characterized by vigor, dedication, and absorption (e. g. 41). We expect that the expression of compassion and sympathy leads to a positive reinforcement of meeting one's jobrequirements. In other words, undertakers might "see themselves as to be able to deal well with the demands of their job" which is typical for engaged employees (41, p. 702). Moreover, when expressing these emotions, they experience a stronger person-job-fit by behaving in correspondence to their job duties and environment which leads to positive work outcomes (see also 42). Clients may also express gratitude towards their undertakers in appreciation of their (authentic) expression of compassion and sympathy. So, undertakers may in turn experience meaningfulness and responsibility 
in their work that fosters internal motivation and engagement $(13,43)$. Thus, according to AET, the association between compassion eliciting work events and work engagement should be mediated by the expression of compassion and sympathy.

H3: The display of compassion and sympathy functions as a mediator between compassion eliciting work events and work engagement.

\subsection{Individual commitment to emotional display rules, display of compassion and sympathy and work engagement}

Our study also seeks to examine the potential role of inter-individual differences in the immediate generation and regulation of emotions at work. To investigate this question, we investigate the possible moderating influence of commitment to display compassion and sympathy (44) as an important feature of the personality of employees. Display rules provide general standards for the appropriate expression of emotions as part of the job, and the occupational or organizational context (45-47). Accordingly, they prescribe behaviour and shape employees emotional displays necessary for facilitating the attainment of organizational objectives $(48,49)$. As stated above, we propose that expressing compassion and sympathy is an important business goal for the profession of undertakers. Thus, employees working in this business (for some time) should have a strong orientation towards feeling and showing these emotions. Moreover, the importance of these rules will be salient for undertakers. However, Gosserand and Diefendorff (44) have shown that not only the presence but also the commitment to such rules influences emotional expressions. Accordingly, we investigate both, the presence and commitment to display rules linked to the display of compassion and sympathy (abbreviated below by 'commitment to display compassion'). As previously discussed and in line with the person-based approach in ASA theory (Attraction-Selection-Attrition, 50), we principally expect both a high level of presence of and commitment to display compassion. ASA theory states not only that personality plays an important factor in selecting jobs and retaining in there but also for constituting and defining settings at work (50). Thus, undertakers might have selected their job and feel a strong person-job fit because they are already strongly committed to display compassion. We therefore expect to find an interaction between the commitment to display compassion and the presence of compassion eliciting work events. For undertakers with high commitment, the level of 
compassion eliciting work events should be less relevant for their expression of compassion. In other words, undertakers with high commitment to display compassion already express compassion and sympathy to a great extent in a genuine way independent from situational cues. For undertakers with low commitment, the occurrence of these work events is more important for influencing their emotional expressions. Thus, our last hypothesis is:

H4: The relationship between compassion eliciting work events and display of compassion and sympathy is moderated by the commitment to display compassion. The association is stronger if this commitment is low.

\section{Methods}

We report how we determined our sample size, all data exclusions (if any), all manipulations, and all measures in the study in accordance with research transparency guidelines (51).

\subsection{Procedure and Participants}

Questionnaires were distributed amongst undertakers at funeral homes in Berlin and Brandenburg, Germany. The sample size was determined by the availability of undertakers in Berlin, hence it is a convenience sample. Each funeral home was visited in person to increase response rates. The undertakers were invited to complete the questionnaire and return it anonymously. In total, we collected data from 112 participants working in at least 56 different funeral homes, because of the anonymity of responses it could not be determined exactly from how many funeral homes the questionnaires were received. 63,6\% were women and 36.4\% were men, all aged between 21 and 77 years $\left(M_{\mathrm{Age}}=47.93, S D_{\mathrm{Age}}=11.45\right)$. The average job tenure was 11.95 years ranging from 0.5 years to 43 years $\left(S D_{\text {jobtenure }}=9.41\right)^{1}$. Procedures were in accordance with the 1964 Helsinki declaration and its later amendments or comparable ethical standards and all participants provided written informed consent.

\footnotetext{
1 Generic job duties of participants ranged from advising and serving clients, providing guidance, selling
} funeral materials, undertaking administration work (organizing), managing visits to the authorities. 


\subsection{Measures}

\subsubsection{Affective Work Events}

Based on our pilot study which we conducted to identify affective work events eliciting different emotions in undertakers (see above), we developed a new instrument for assessing these affective work events. We formulated items regarding the events that are considered to be related to positive emotions (pride, joy, contentment), compassion and sympathy. To ensure construct validity of these new items, we compared the assessed events (e.g., recognition, appreciation) to prior research on emotions and affective events (e. g. 17, 18, 23). Prior to data collection, we further conducted a pretest with five other undertakers to ensure that these new items are understandable. Our final scale for measuring the occurrence of positive work events consists of six items concerning joy, pride, and contentment (see Table 2). Compassion eliciting work events were measured with two items concerning compassion and sympathy, due to low discriminatory power a third item was deleted.

\subsubsection{Work design features}

Job autonomy was measured by six items from WDQ (52), taken from the work-scheduling and decision-making autonomy subscales. Examples are 'the job allows me to make my own decisions about how to schedule my work' and 'the job provides me with significant autonomy in making decisions'. All items were to be answered on a 5-point Likert scale ( $1=$ 'strongly disagree' to $5=$ 'strongly agree'). Time pressure was assessed by four items taken from ISTA (53) e. g., 'How often do you have to miss or delay a break because of too much work?' rated on a 5-point Likert scale ranging from 1 = 'very rarely/never' to 5 = 'very often'.

\subsubsection{Display of emotions}

The display of positive emotions and the display of compassion and sympathy were measured by corresponding items taken from the 'expression emotions you feel' subscale from Discrete Emotions Emotional Labour Scale (DEELS, 54). The display of positive emotions was assessed by three equal items concerning joy, pride, and contentment. The sample item for joy is 'how often do you express joy when you feel that way'. Analogously, the display of compassion and sympathy was 
measured separately for compassion and sympathy. All these items ranged on a 5-point Likert scale (1 $=$ 'never' to $5=$ 'many times a day').

\subsubsection{Commitment to display rules}

Commitment to display compassion and sympathy were assessed using four items adopted from Gosserand and Diefendorff (44). Participants were asked whether they agreed that display rules are present and about the extent to which they feel committed to those rules. Sample items for compassion are 'In my job it is desirable to show feelings of compassion when dealing with clients', and 'I feel committed to fulfilling the expectation to show compassion' ranging on a 5-point Likert scale $(1=$ 'strongly disagree' to $5=$ 'strongly agree' $)$. We did not assess commitment to display positive emotions, as positive emotions are not considered occupation specific.

\subsubsection{Job satisfaction and work engagement}

Job satisfaction was measured by four items taken from Diefendorff, Erickson (49), e.g., 'how satisfied are you with your work in general' ranging on a 5-point Likert scale from $1=$ 'very dissatisfied' to $5=$ 'very satisfied'. Work engagement was assessed by UWES-9 comprising nine items (41), e.g., 'I am proud of the work that I do' with a 7-point Likert scale $(0=$ 'never' to $6=$ 'always/everyday').

\subsubsection{Control variables}

In all analyses we controlled for age, gender, and job tenure because these variables have been found to be correlated with the other specified variables. There is (meta-analytical) evidence for gender and age differences in emotional expressions (55-57), while Denton and Kleiman (58) demonstrated a moderating effect of job tenure on job autonomy and job satisfaction. All items were presented in German, providing a high internal consistency (see Table 3).

Additional variables that were measured but which are not of interest for the current research questions were: occupation/task, well-being (WHO-5, 59), Organizational Identification (OIQ, 60), Emotional Exhaustion (EE subscale of the Maslach Burnout Inventory, 61). 


\subsection{Data analysis}

Data analysis was conducted using IBM SPSS Statistics 21. PROCESS, a macro tool designed by Hayes (62), which enables bootstrapping confidence intervals of indirect effects, was applied to test all hypotheses. In the moderation model of $\mathrm{H} 4$, all variables were automatically mean centered by PROCESS (62). 5000 bootstrap samples were used to compute 95 percent confidence intervals.

\section{Results}

Descriptive statistics, inter-correlations of all study variables and scales' internal consistencies are presented in Table 3.

\subsection{Analysis of common-method variance}

To address potential common-method variance between the assessed variables, we tested whether more than $50 \%$ of the variance could be explained by a single, general factor conducting a Harman's single factor test (63).. An unrotated factor solution of all study variables indicated that eigenvalues of the first nine factors $(2.87,1.56,1.14, .89, .75, .60, .52, .41, .27)$ explained $31.87 \%$, $17.32 \%, 12.67 \%, 9.88 \%, 8.34 \%, 6.65 \%, 5.75 \%, 4.52 \%, 3.01 \%$ of the total variance. So, the variance explained by one factor is less than $50 \%$ and common method variance seems to be unproblematic in this data set.

\subsection{Test of Hypothesis $\mathrm{H1}$}

To test H1, a serial multiple mediation model was conducted. As Figure 2 shows, job autonomy had a direct, positive relationship to job satisfaction $\left(c_{1}=.13, p<.05\right)$. Moreover, it was found to significantly predict the occurrence of positive work events $\left(a_{1}=.18, p<.05\right)$. Positive work events were significantly related to the display of positive emotions $\left(a_{3}=.38, p<.01\right)$, and this was, in turn, a predictor of job satisfaction $\left(b_{2}=.24, p<.01\right)$. The bootstrap estimate of all total indirect effects was $c_{2}=.05(S E=.03,95 \%$ CI $[.005, .115])$. The partial sequential indirect effect (Mediator $1 *$ Mediator2) was also significant $\left(c_{3}=.02, S E=.01,95 \%\right.$ CI $\left.[.003, .459]\right)$. The total model explained a considerable amount of variance in job satisfaction $\left(R^{2}=.248, F(6,97)=5.34, p<.01\right)$. Thus, H1was fully supported. 
- $\quad$ insert Figure 2 about here -

\subsection{Test of Hypothesis $\mathrm{H2}$}

$\mathrm{H} 2$ states that the relationships between job autonomy and the display of positive emotions, as well as between display of positive emotion and job satisfaction in the mediation model are both moderated by time pressure. Job autonomy had a small direct, positive relationship to job satisfaction $\left(c_{l}=.11, p=.06\right)$, although it failed to reach significance. However, job autonomy significantly predicted the display of positive emotions $\left(a_{1}=.23, p<.05\right)$. In turn, display of positive emotions was significantly related to job satisfaction $\left(a_{2}=.26, p<.001\right)$. There was neither a moderation effect of time pressure on the association between job autonomy and display of positive emotions $(\beta=.14, \mathrm{p}=$ $.17)$, nor on the association between display of positive emotions and job satisfaction $(\beta=-.06, \mathrm{p}=$ .42). However, we found different conditional bootstrap estimates of total indirect effects: for low time pressure $\left(-1 \mathrm{SD}, c_{2 l o w}=.03, \mathrm{SE}=.04,95 \% \mathrm{CI}[-.055, .116]\right)$, for medium time pressure $\left(+-0 \mathrm{SD}, c_{2 \text { medium }}\right.$ $=.06, \mathrm{SE}=.03,95 \% \mathrm{CI}[.011, .120])$, and for high time pressure $\left(+1 \mathrm{SD}, c_{2 h i g h}=.07, \mathrm{SE}=.04,95 \% \mathrm{CI}\right.$ $[.018, .152])$. The total model explained a considerable amount of variance in job satisfaction $\left(R^{2}=\right.$ $.287, F(7,96)=5.53, p<.001)$.

To disentangle this finding, we conducted an additional analysis and divided the sample into two equal groups via a median split of the proposed moderator time pressure $(<M D$ and $>M D$ of time pressure). Next, two simple mediation models were conducted and the results of both groups were compared (see Figure 3). For undertakers indicating low levels of time pressure, job autonomy and display of positive emotions were not significantly related $\left(a_{l}=.03\right.$, n.s. $)$. In comparison, for undertakers indicating high levels of time pressure the association between the two variables was significant $\left(a_{1}=.41, p<.01\right)$, see Figure 3$)$. This finding supports our reasoning underlying $\mathrm{H} 2$. Furthermore, the relationship between display of positive emotions and job satisfaction was significant $\left(a_{2}=.30, p<.01\right)$ in undertakers indicating low levels of time pressure, but weaker for undertakers indicating high levels of time pressure $\left(a_{2}=.16, p<.05\right.$, see Figure 3$)$. For undertakers with low levels of time pressure, job autonomy was not significantly related to job satisfaction $\left(c_{1}=.10\right.$, n.s. $)$, and an indirect effect could not be found as well $c_{2}=.01(S E=.04,95 \%$ CI $[-.073, .103])$. However, 
for undertakers with high levels of time pressure, job autonomy was directly related to job satisfaction $\left(c_{1}=.16, p<.05\right)$, and indirectly $\left(c_{2}=.07(S E=.03,95 \%\right.$ CI $[.017, .160])$, supporting again our assumptions concerning a moderating influence of time pressure. The explained variance in job satisfaction was $R^{2}=.256(F(5,46)=3.17, p<.02)$ for undertakers with low levels of time pressure, the corresponding results for undertakers with high levels of time pressure were $R^{2}=.315(F(5,46)=$ 4.23, $p<.00)$. In sum, $\mathrm{H} 2$ was supported.

- $\quad$ insert Figure 3 about here -

\subsection{Test of Hypothesis $\mathrm{H3}$ and $\mathrm{H} 4$}

A moderated mediation model was conducted to test $\mathrm{H} 3$ and $\mathrm{H} 4$ (see Figure 4), and simultaneously a moderated regression model was applied to specify the interaction pattern. As predicted, compassion eliciting work events were found to significantly predict the display of compassion and sympathy $(B=.43, p<.01)$. Moreover, the display of compassion and sympathy was positively related to work engagement $(B=.33, p<.01)$. Compassion eliciting work events, after controlling for the display of compassion and sympathy, no longer significantly predicted work engagement $(B=.17, n . s$.$) , indicating a full mediation. In total, 14 \%$ of work engagement was explained by this model $\left(R^{2}=.142, F(5,100)=3.32, p<.01\right)$.

- $\quad$ insert Figure 4 about here -

In order to check for moderating effects of commitment to display compassion on the relationship between compassion eliciting work events and the expression of compassion and sympathy, we analyzed and found that commitment to display compassion $(B=.18, p<.05)$ as well as the proposed interaction term $(B=-.27, p<.01)$ were significantly related to these emotional expressions. Secondly, the moderated regression specified the details: $\mathrm{R}^{2}$ increased significantly due to the interaction term $\left(\Delta R^{2}=.049, F(1,99)=7.35, p<.01\right)$. The interaction pattern was analyzed by plotting compassion eliciting work events on different values of commitment to display compassion 
(one standard deviation above and one standard deviation below the mean, see Figure 5) Cohen,

Cohen (64). As Figure 5 indicates and as predicted, with increases from lower to higher levels of compassion eliciting work events, display of compassion and sympathy increased much stronger in undertakers with low levels of commitment. Subsequently, simple slopes were inspected. When commitment to display compassion was low, increasing specific work events led to more display of compassion and sympathy $(B=.70, t=5.07, p<.01$ vs. for high levels: $B=.17, t=1.30, n . s$.$) .$

- $\quad$ insert Figure 5 about here -

Subsequently, in the moderated-mediation model, the conditional indirect effects of the mediator at different values of the moderator on work engagement were inspected and indicated similar results. The indirect effect of the display of compassion and sympathy was found to be significant when commitment to display compassion was below the mean $(B=.23, S E=.08,95 \% \mathrm{CI}$ $[.083, .410])$, and at the mean $(B=.14, S E=.06,95 \%$ CI $[.045, .265])$, but non-significant for one standard deviation above the mean $(B=.06, S E=.05,95 \%$ CI $[-.023, .199])$. Taken together, $\mathrm{H} 3$ and H4 were fully supported.

\section{Discussion}

The main goal of our study was to explore the "emotional landscape" in the service profession of undertakers. Therefore, we first identified possible affective work events (positive work events, compassion eliciting work events) in a qualitative explorative study. In the main (quantitative) study, these events were investigated in their association with different emotions (positive emotions as well as occupation specific emotions like compassion and sympathy), individual differences in the commitment to display compassion, and in their association with important work outcomes (job satisfaction, work engagement). Furthermore, and following suggestions of Grandey and Melloy (19) we provided first empirical evidence of an expanded AET model which captures situational work features (time pressure) not only as a potential cause of work events that can elicit affective 
experiences at work but also as a moderator affecting emotion regulation after the experience of emotions (see Figure 1).

Our study highlights that job characteristics (i. e. job autonomy) influence job satisfaction both in a direct, and in an indirect way via the occurrence of positive work events and the display of positive emotions. Previous results on AET (e.g., 7, 8) could thus be confirmed also in undertakers' work. In our opinion, this finding is important because the service work of undertakers is characterized by many situations in which the display of positive emotions might be inappropriate, in particular in direct client interactions. Our results therefore underscore past research concerning positive work events: Independent from the work setting, it seems that positive work events are related to the expression of the corresponding emotions, as, for instance, pride events (e. g., recognition) that are almost always related to the expression of pride $(18,65)$. Thus, also in professions in which positive emotions might be problematic, one can conclude that it is beneficial to foster positive work events for an increase in subjective well-being of service providers.

In line with these findings, we demonstrated an association between compassion eliciting work events and work engagement mediated by the display of compassion and sympathy. One might conclude that regulating these occupation specific emotions is perceived as a work challenge that corresponds with higher levels of work engagement (see also 66). As an alternative, detailed in Yu (67), these affective experiences might end up in higher levels of person job fit, being associated with positive work outcomes. Of course, it is also well-known that personality and individual differences in emotion related abilities is important for experiencing the specific situational events and emotions at work $(6,19,65,68)$.

Thus, as expected, we found support for our idea that commitment to display compassion interacts with compassion eliciting work events and the display of compassion and sympathy. Undertakers indicating high levels of commitment do strongly express compassion and sympathy in general. The emotional change depending on the occurrence of specific work events is, therefore, only significant for undertakers with low levels to express compassion and sympathy.

Finally, our study provides first empirical insights of an expanded AET model that covers possible interaction effects of situational work features. Similar to past research, we found that high 
levels of time pressure increase the display of positive emotions in service tasks (35), whereas the same conditions might alleviate the relationship between the experienced positive emotions and job satisfaction. Under these circumstances, positive emotions might be experienced in a less genuine way and therefore might be related to decreased job satisfaction (for more details, also on surface acting, see 40). Thus, organizations might consider monitoring their employees' time pressure to prevent downside influences on subjective well-being. Taken together, our idea to extend AET by integrating work features (e.g., time pressure) after the elicitation of emotions seems to be promising.

\subsection{Limitations and future direction}

Several limitations of this study should be taken into account. First, cross-sectional data cannot answer questions of causality. However, given the findings from longitudinal and experimental research (16 WOS:000175569600002, 65), we think that our basic findings might, at least partly, remain valid in longitudinal research. With respect to the fact that our sample, even though comparatively small, consists of undertakers from at least 56 funeral homes, we have reasons to believe that our results are reflective of a larger population of undertakers. Nonetheless, longitudinal studies are encouraged. Second, this study relied on self-report data which can possibly lead to common method effects. However, our single factor test indicated no confounding effects. Moreover, these problems are being discussed as to be overstated (69), and the various interactions we predicted and found in this study cannot be influenced by common method effects (70). In the same vein, it remains difficult to measure the present varia-bles (e.g., job satisfaction) with other methods. In addition, emotional evaluations and physio-logical responses are correlated and strongly consistent with each other $(71,72)$. The method used should therefore be chosen with regard to the research question. Since ours was not to investigate physiological components of emotions, self-report data is acceptable.

Another limitation concerns the methodological approach to test possible moderating influences of time pressure. By using a dichotomization of time pressure (via median split), categorical information is lost which might affect the results (73). Therefore, we recommend using a larger sample to increase power and be able to reveal smaller conditional mediation effects for a replication of these findings in future studies. 
Also the correlation between gender and the expression of emotions and commitment to display compassion which we found in our data could be elabourated further. Our findings suggest that women not only express more compassion and sympathy, but also experience a stronger presence of and commitment to display rules for showing these emotions. The research stream regarding empathetic concern at work shows similar findings concerning women (74). Therefore, it makes sense to test practical implications and whether a generalization of these effects across occupations is possible.

Moreover, we recommend considering other personality dispositions (e.g., positive or negative affectivity) when further analyzing undertakers' work. In a similar vein, an investigation of the suppression of emotions and their corresponding work events, which both were not within the scope of this study, could further advance research. Finally, future studies focusing on specific work events should also take into account the detailed classification of positive and negative work events developed by (18). This taxonomy provides future guidance for analyzing work events and could be also used for a comparison across occupations, investigating also the role of differences in organizational service climate.

\subsection{Conclusion}

Taken together, our findings do not only support the importance of integrating specific affective work events into research designs when examining emotions in service work. They also point out that a further consideration of situational work features such as having high or low time pressure in service encounters after the elicitation of emotions is important. We therefore recommend to utilize an expanded model of affective events theory in future research on service work. Such an extended model will be helpful in attaining a more comprehensive understanding of possible influences of emotions, emotional dissonance and their regulation in service encounters. As shown in this study focusing on the work of undertakers, inter-individual differences in commitment to display compassion to clients suffering bereavement moderate requirements for emotional labour. This supports once again a more complex approach in which personality is considered in relation to emotional labour as well as possible work outcomes. Integrating this research approach with data focusing on customer behaviour and customer reactions in service work seems very worthwhile. Finally, our study clearly indicates 
Affective Work Events and Emotions amongst Undertakers

This is a preprint of a manuscript submitted to WORK

again that the analysis of specific emotions at work complements traditional psychological models

focusing on job satisfaction as an indicator of employee well-being and should therefore be reinforced in research on occupational health. 


\section{References}

1. Gross JJ. Emotion Regulation: Conceptual and Empirical Foundations. In: Gross JJ, editor. Handbook of Emotion Regulation. 2. New York London: The Guilford Press; 2014. p. 3-20.

2. Nerdinger FW. Emotional Labor in the 21st Century. Diverse Perspectives on Emotion Regulation at Work. Z Arb Organ. 2013;57(3):154-U60.

3. Grandey AA, Diefendorff JM, Rupp DE. Emotional Labor in the 21st Century. Diverse Perspectives on Emotion Regulation at Work. New York: Routledge; 2013.

4. Ashkanasy NM, Dorris AD. Emotions in the Workplace. Annual Review of Organizational Psychology and Organizational Behavior. 2017;4(1):67-90.

5. Troth AC, Lawrence SA, Jordan PJ, Ashkanasy NM. Interpersonal Emotion Regulation in the Workplace: A Conceptual and Operational Review and Future Research Agenda. International Journal of Management Reviews. 2018;20(2):523-43.

6. Fisher CD. Happiness at Work. International Journal of Management Reviews. 2010;12(4):384412.

7. Meeusen VCH, Brown-Mahoney C, van Dam K, van Zundert AAJ, Knape JTA. Personality dimensions and their relationship with job satisfaction amongst dutch nurse anaesthetists. J Nurs Manage. 2010;18(5):573-81.

8. Wegge J, van Dick R, Fisher GK, West MA, Dawson JF. A test of basic assumptions of affective events theory (AET) in call centre work. British Journal of Management. 2006;17(3):237-54.

9. Zapf D, Holz M. On the positive and negative effects of emotion work in organizations. European Journal of Work and Organizational Psychology. 2006;15(1):1-28.

10. Fischbach A, Lichtenthaler PW. Nutzung und Effekte von Emotionen und Regulationsstrategien Ergebnisse einer Befragung von Polizeiführungskräften und ihren Mitarbeitenden. Praeview Zeitschrift für innovative Arbeitsgestaltung und Prävention. 2012;4:10-1.

11. Hsiao WJ. The Impact of Daily Emotion on Emotional Labor: The Perspective of Affective Events Theory. Ntu Manag Rev. 2014;24(2):249-81.

12. Weiss HM, Cropanzano R. Affective events theory: A theoretical discussion of the structure, causes and consequences of affective experiences at work. Research in Organizational Behavior. 1996;18:1-74.

13. Humphrey SE, Nahrgang JD, Morgeson FP. Integrating motivational, social, and contextual work design features: a meta-analytic summary and theoretical extension of the work design literature. Journal of Applied Psychology. 2007;92(5):1332-56.

14. Fila MJ, Purl J, Griffeth RW. Job demands, control and support: Meta-analyzing moderator effects of gender, nationality, and occupation. Human Resource Management Review. 2017;27(1):39-60.

15. Allan BA, Dexter C, Kinsey R, Parker S. Meaningful work and mental health: job satisfaction as a moderator. J Ment Health. 2018;27(1):38-44.

16. Fisher $\mathrm{CD}$. Antecedents and consequences of real-time affective reactions at work. Motivation and emotion. 2002;26(1):3-30.

17. Basch J, Fisher C. Affective events-emotions matrix: A classification of work events and associated emotions. In: Ashkanasy NM, Härtel CE, Zerbe WJ, editors. Emotions in the Workplace: Research, Theory, and Practice. Westport, CT USA: Quorum Books/Greenwood Publishing Group; 2000. p. 36-48.

18. Ohly S, Schmitt A. What Makes Us Enthusiastic, Angry, Feeling at Rest or Worried? Development and Validation of an Affective Work Events Taxonomy Using Concept Mapping Methodology. Journal of Business and Psychology. 2015;30(1):15-35.

19. Grandey AA, Melloy RC. The state of the heart: Emotional labor as emotion regulation reviewed and revised. Journal of Occupational Health Psychology. 2017;22(3):407-22.

20. Glaso L, Vie TL, Holmdal GR, Einarsen S. An Application of Affective Events Theory to Workplace Bullying The Role of Emotions, Trait Anxiety, and Trait Anger. Eur Psychol. 2011;16(3):198-208.

21. Bremborg AD. Professionalization without dead bodies: the case of Swedish funeral directors. Mortality. 2006;11(3):270-85.

22. Bailey T. When commerce meets care: Emotion management in UK funeral directing. Mortality. 2010;15(3):205-22. 
23. Scherer KR. What are emotions? And how can they be measured? Soc Sci Inform. 2005;44(4):695-729.

24. Ashton-James CE, Ashkanasy NM. What Lies Beneath? A Process Analysis of Affective Events Theory. In: Ashkanasy NM, Zerbe WJ, Härtel CEJ, editors. The Effect of Affect in Organizational Settings. Research on Emotion in Organizations. 1. Bingley: Emerald Group Publishing Limited; 2005. p. 23-46.

25. Jimmieson NL, Tucker MK, Walsh AJ. Interaction effects among multiple job demands: an examination of healthcare workers across different contexts. Anxiety Stress Copin. 2017;30(3):317-32.

26. Riedl EM, Thomas J. The moderating role of work pressure on the relationships between emotional demands and tension, exhaustion, and work engagement: an experience sampling study among nurses. European Journal of Work and Organizational Psychology. 2019;28(3):414-29.

27. van Woerkom M, Bakker AB, Nishii LH. Accumulative job demands and support for strength use: Fine-tuning the job demands-resources model using conservation of resources theory. Journal of Applied Psychology. 2016;101(1):141-50.

28. Geisler M, Berthelsen H, Hakanen JJ. No Job Demand Is an Island - Interaction Effects Between Emotional Demands and Other Types of Job Demands. Frontiers in psychology. 2019;10:873.

29. Koch A, Strobel A, Miller R, Garten A, Cimander C, Westhoff K. Never Use One When Two Will Do The Effects of a Multi-Perspective Approach on the Outcome of Job Analyses Using the Critical Incident Technique. Journal of Personnel Psychology. 2012;11(2):95-102.

30. Hackman JR, Greg R O. Development of the Job Diagnostic Survey Journal of Applied Psychology. 1975;60(2):159-70.

31. Grandey AA. Emotion regulation in the workplace: a new way to conceptualize emotional labor. Journal of Occupational Health Psychology. 2000;5(1):95-110.

32. Sekerka LE, Vacharkulksemsuk T, Fredrickson BL. Positive emotions broadening and building upward spirals of sustainable enterprise. In: Cameron KS, Spreitzer GM, editors. The Oxford Handbook of Positive Organizational Sholarship. New York, NY US: Oxford University Press; 2012. p. 168-77.

33. Wegge J, Van Dick R, von Bernstorff C. Emotional dissonance in call centre work. Journal of Managerial Psychology. 2010;25(6):596-619.

34. Podsakoff NP, LePine JA, LePine MA. Differential challenge stressor-hindrance stressor relationships with job attitudes, turnover intentions, turnover, and withdrawal behavior: A metaanalysis. Journal of Applied Psychology. 2007;92(2):438-54.

35. Rafaeli A, Sutton RI. Busy Stores and Demanding Customers - How Do They Affect the Display of Positive Emotion. Academy of Management Journal. 1990;33(3):623-37.

36. Kühnel J, Sonnentag S, Bledow R. Resources and time pressure as day-level antecedents of work engagement. Journal of Occupational and Organizational Psychology. 2012;85(1):181-98.

37. Bakker AB, Demerouti E. Job Demands-Resources Theory: Taking Stock and Looking Forward. Journal of Occupational Health Psychology. 2016.

38. Karasek RA. Job Demands, Job Decision Latitude, and Mental Strain - Implications for Job Redesign. Admin Sci Quart. 1979;24(2):285-308.

39. Giardini A, Frese M. Reducing the negative effects of emotion work in service occupations: emotional competence as a psychological resource. J Occup Health Psychol. 2006;11(1):63-75.

40. Mesmer-Magnus JR, DeChurch LA, Wax A. Moving emotional labor beyond surface and deep acting: A discordance-congruence perspective. Organizational Psychology Review. 2012;2(1):653.

41. Schaufeli WB, Bakker AB, Salanova M. The measurement of work engagement with a short questionnaire - A cross-national study. Educ Psychol Meas. 2006;66(4):701-16.

42. Oh IS, Guay RP, Kim K, Harold CM, Lee JH, Heo CG, et al. Fit Happens Globally: A MetaAnalytic Comparison of the Relationships of Person-Environment Fit Dimensions with Work Attitudes and Performance across East Asia, Europe, and North America. Personnel Psychology. 2014;67(1):99-152.

43. Rothbard NP, Patil SV. Being there. Work engagement and positive organizational scholarship. In: Cameron KS, Spreitzer GM, editors. The Oxford Handbook of Positive Organizational Scholarship. New York, NY US: Oxford University Press; 2012. p. 56-68. 
44. Gosserand RH, Diefendorff JM. Emotional display rules and emotional labor: The moderating role of commitment. Journal of Applied Psychology. 2005;90(6):1256-64.

45. Grandey AA, Sayre GM. Emotional Labor: Regulating Emotions for a Wage. Curr Dir Psychol Sci. 2019;28(2):131-7.

46. Grandey AA, Rupp D, Brice WN. Emotional labor threatens decent work: A proposal to eradicate emotional display rules. Journal of Organizational Behavior. 2015;36(6):770-85.

47. Fischbach A, Meyer-Gomes K, Zapf D, Rank J. Emotion work across cultures: A comparison between the United States and Germany. In: Zerbe WJ, Ashkanasy NM, Härtel CEJ, editors. Individual and Organizational Perspectives on Emotion Management and Display Research (Emotion in Organizations, Volume 2) Emerald Group Publishing Limited,; 2006. p. 193-217.

48. Diefendorff JM, Richard EM. Antecedents and consequences of emotional display rule perceptions. Journal of Applied Psychology. 2003;88(2):284-94.

49. Diefendorff JM, Erickson RJ, Grandey AA, Dahling JJ. Emotional Display Rules as Work Unit Norms: A Multilevel Analysis of Emotional Labor Among Nurses. Journal of Occupational Health Psychology. 2011;16(2):170-86.

50. Schneider B, Goldstein HW, Smith DB. The ASA framework: An update. Personnel Psychology. 1995;48(4):747-73.

51. Simmons JP, Nelson LD, Simonsohn U. A 21 Word Solution. Dialogue - The Official Newsletter of the Society for Personality and Social Psychology. 2012;26(2):4-7.

52. Stegmann S, van Dick R, Ullrich J, Charalambous J, Menzel B, Egold N, et al. Der Work Design Questionnaire - Vorstellung und erste Validierung einer deutschen Version. . Z Arb Organ. 2010;54(1):1-28.

53. Semmer NK, Zapf D, Dunckel H. Assessing stress at work: A framework and an instrument. Luxembourg: Office for Official Publications of the European Communities; 1995.

54. Glomb TM, Tews MJ. Emotional labor: A conceptualization and scale development. Journal of Vocational Behavior. 2004;64(1):1-23.

55. Fischer AH, Rodriguez Mosquera PM, van Vianen AE, Manstead AS. Gender and culture differences in emotion. Emotion. 2004;4(1):87-94.

56. Manstead ASR. Gender differences in emotion. In: Gale A, Eysenck MW, editors. Wiley psychophysiology handbooks Handbook of individual differences: Biological perspectives: John Wiley \& Sons; 1992. p. 355-87.

57. Chaplin TM, Aldao A. Gender differences in emotion expression in children: a meta-analytic review. Psychol Bull. 2013;139(4):735-65.

58. Denton DW, Kleiman LS. Job Tenure as a Moderator of the Relationship Between Autonomy and Satisfaction. Applied HRM Research. 2001;6(2):105-14.

59. Brähler E, Mühlan, H., Albani, C., \& Schmidt, S. Teststatistische Prüfung und Normierung der deutschen Versionen des EUROHIS-QOL-Lebensqualität-Index und des WHO-5 WohlbefindensIndex. Diagnostica. 2007;53 (2):83-96.

60. Miller VD, Allen M, Casey MK, Johnson JR. Reconsidering the Organizational Identification Questionnaire. Management Communication Quarterly. 2016;13(4):626-58.

61. Bussing A, Perrar KM. Die Messung von Burnout: Untersuchung einer deutschen Fassung des Maslach Burnout Inventory (MBI-D) [Measurement of Burnout: Analysis of a German Version of the Maslach Burnout Inventory]. . Diagnostica. 1992;38:328-53.

62. Hayes AF. Introduction to mediation, moderation, and conditional process analysis: A regressionbased approach. New York: Guilford Press; 2013.

63. Podsakoff PM, MacKenzie SB, Lee JY, Podsakoff NP. Common method biases in behavioral research: a critical review of the literature and recommended remedies. Journal of Applied Psychology. 2003;88(5):879-903.

64. Cohen J, Cohen P, West SG, Aiken LS. Applied multiple regression/correlation analysis for the behavioral sciences. Mahwah, NJ US: Lawrence Erlbaum Associates Publishers; 2003.

65. Grandey AA, Tam AP, Brauburger AL. Affective states and traits in the workplace: Diary and survey data from young workers. Motivation and emotion. 2002;26(1):31-55.

66. Xanthopoulou D, Bakker AB, Fischbach A. Work Engagement Among Employees Facing Emotional Demands The Role of Personal Resources. Journal of Personnel Psychology. 2013;12(2):74-84. 
67. Yu KYT. Affective Influences in Person-Environment Fit Theory: Exploring the Role of Affect as Both Cause and Outcome of P-E Fit. Journal of Applied Psychology. 2009;94(5):1210-26.

68. Rubino C, Perry SJ, Milam AC, Spitzmueller C, Zapf D. Demand-control-person: integrating the demand-control and conservation of resources models to test an expanded stressor-strain model. Journal of Occupational Health Psychology. 2012;17(4):456-72.

69. Spector PE. Method variance in organizational research - Truth or urban legend? Organ Res Methods. 2006;9(2):221-32.

70. Siemsen E, Roth A, Oliveira P. Common Method Bias in Regression Models With Linear, Quadratic, and Interaction Effects. Organ Res Methods. 2010;13(3):456-76.

71. Lang PJ, Greenwald MK, Bradley MM, Hamm AO. Looking at Pictures - Affective, Facial, Visceral, and Behavioral Reactions. Psychophysiology. 1993;30(3):261-73.

72. Levenson RW. Blood, sweat, and fears: the autonomic architecture of emotion. Ann N Y Acad Sci. 2003;1000:348-66.

73. MacCallum RC, Zhang SB, Preacher KJ, Rucker DD. On the practice of dichotomization of quantitative variables. Psychological methods. 2002;7(1):19-40.

74. Gleichgerrcht E, Decety J. Empathy in clinical practice: how individual dispositions, gender, and experience moderate empathic concern, burnout, and emotional distress in physicians. PloS One. 2013;8(4):e61526. 


\section{Table Captions}

Table 1: Affective work events related to different emotions among undertakers

Table 2: A new measurement of affective work events related to positive emotions, compassion and sympathy among undertakers

Table 3: Means, Standard Deviations, and Inter-correlations among Variables and Scales' Internal Consistencies 


\section{Tables}

Table 1

\begin{tabular}{|c|c|}
\hline $\begin{array}{l}\text { Corresponding } \\
\text { emotions }\end{array}$ & Affective work events \\
\hline \multirow{6}{*}{$\begin{array}{l}\text { Joy, pride, } \\
\text { contentment }\end{array}$} & Clients thank the undertakers for a good counseling \\
\hline & Clients say that the funeral service has run smoothly \\
\hline & Clients state that the undertakers have helped them well in a very difficult situation \\
\hline & Undertakers' personal contribution makes an initially difficult farewell turn out acceptable \\
\hline & \\
\hline & $\begin{array}{l}\text { despite initial difficulties } \\
\text { Undertakers are told that they have carried out all tasks to the clients' satisfaction }\end{array}$ \\
\hline \multirow{3}{*}{$\begin{array}{l}\text { Compassion } \\
\text { and sympathy }\end{array}$} & Undertakers get a very nice family as a client that they immediately like \\
\hline & Undertakers do a special favor because of personal affection by the clients' fate \\
\hline & Undertakers relate the fate of their clients to their own life or their own fate respectively \\
\hline \multirow[t]{4}{*}{ Anger } & Clients are not thankful towards the undertakers even if the undertakers have put much effort in the funeral \\
\hline & Clients complain afterwards about being dissatisfied with the provided service \\
\hline & Clients behave inappropriately or unfriendly towards the undertakers \\
\hline & Clients complain about trifles (e.g., mistakes in grief printings) \\
\hline Disgust & Undertakers face a particularly bad appearance or very unpleasant smell of a descendent \\
\hline Sadness & Discrepancies occur at the funeral which undertakers cannot repair afterwards \\
\hline Antipathy & $\begin{array}{l}\text { Clients complain about being dissatisfied with the quality of the funeral } \\
\text { Undertakers get a client that they immediately dislike }\end{array}$ \\
\hline
\end{tabular}


Table 2

\begin{tabular}{|c|c|}
\hline Corresponding emotions & Items concerning affective work events \\
\hline \multirow{2}{*}{$\begin{array}{l}\text { Joy, pride, contentment } \\
\text { ('positive work events') }\end{array}$} & How often do your clients thank you for your good counseling? \\
\hline & $\begin{array}{l}\text { How often do your clients say that the funeral service has run smoothly? } \\
\text { How often do your clients state that you have helped them well in a very } \\
\text { difficult situation? } \\
\text { How often does your personal contribution make an initially difficult farewell } \\
\text { turn out acceptable? } \\
\text { How often can you fulfill special wishes of clients (e.g., a certain cemetery, } \\
\text { certain day) } \\
\text { although it has been difficult in the beginning? } \\
\text { How often are you told that you have carried out all tasks to your client's } \\
\text { satisfaction? }\end{array}$ \\
\hline $\begin{array}{l}\text { Compassion and sympathy } \\
\text { ('compassion eliciting } \\
\text { work events') }\end{array}$ & $\begin{array}{l}\text { How often do you get a very nice family as your client that you immediately } \\
\text { like? } \\
\text { How often do you do your client a special favor because you are personally } \\
\text { affected by his fate? } \\
\text { How often do you relate the fate of your clients to your own life or your own } \\
\text { fate, respectively?* }\end{array}$ \\
\hline
\end{tabular}

Note. *this item has been excluded from the analysis due to very low discriminatory power. 
Table 3

\begin{tabular}{|c|c|c|c|c|c|c|c|c|c|c|c|c|c|c|c|}
\hline & & $M$ & $S D$ & 1 & 2 & 3 & 4 & 5 & 6 & 7 & 8 & 9 & 10 & 11 & 12 \\
\hline 1 & Age & 47.93 & 11.45 & & & & & & & & & & & & \\
\hline 2 & Gender $($ women $=1$, men $=2)$ & 1.36 & 0.48 & -.06 & & & & & & & & & & & \\
\hline 3 & Job tenure & 11.95 & 9.41 & $.50^{* *}$ & .11 & & & & & & & & & & \\
\hline 4 & Positive work events & 3.21 & 0.91 & -.07 & $-.25 * *$ & -.03 & $(.90)$ & & & & & & & & \\
\hline 5 & Compassion eliciting work events & 2.93 & 0.96 & -.01 & $-.35 * *$ & -.02 & $.68^{* * *}$ & $(.78)$ & & & & & & & \\
\hline 6 & Job autonomy & 3.36 & 1.11 & .03 & .02 & $.22 *$ & $.21 *$ & .14 & $(.93)$ & & & & & & \\
\hline 7 & Time pressure & 3.29 & 0.85 & -.16 & $.23^{*}$ & -.07 & .15 & .04 & -.16 & $(.85)$ & & & & & \\
\hline 8 & Display of positive emotions & 2.94 & 1.00 & -.15 & -.03 & $-.21 *$ & $.37 * *$ & $.35^{* *}$ & .17 & .14 & $(.76)$ & & & & \\
\hline 9 & Display of compassion, sympathy & 3.71 & 1.02 & -.01 & $-.33 * *$ & -.15 & $.36^{* * *}$ & $.46^{* *}$ & .10 & .16 & $.40^{* *}$ & $(.78)$ & & & \\
\hline 10 & Commitment to display compassion & 3.94 & 0.98 & -.03 & $-.23 *$ & -.15 & .09 & .10 & -.01 & -.07 & .02 & $.27 * *$ & (.84) & & \\
\hline 11 & Work engagement & 4.49 & 1.13 & -.09 & .08 & .00 & $.29 * *$ & $.24 * *$ & $.30^{* *}$ & .06 & $.39 * *$ & $.26^{* *}$ & -.03 & $(.94)$ & \\
\hline 12 & Job satisfaction & 4.04 & 0.67 & $.22 *$ & -.04 & .18 & .18 & .12 & $.31^{* *}$ & $-.20 * *$ & $.34 * *$ & .05 & -.11 & $.49 * *$ & $(.74)$ \\
\hline
\end{tabular}

Note. $N=112 .{ }^{*} p<.05,{ }^{* *} p<.01$. Cronbach's alphas are presented in parentheses. 


\section{Figure Captions}

Figure 1: Theoretical overview of an extended model of affective events theory, based on Weiss and Cropanzano (12); the direct path between work features and job satisfaction is the 'cognitive route', the indirect path via the occurrence of work events and emotions is the 'affective route'.

Figure 2: Multiple mediation model (including path coefficients) on job satisfaction; Note. $\mathrm{N}=104$ due to single missing values, ${ }^{*} \mathrm{p}<.05,{ }^{* *} \mathrm{p}<.01, \mathrm{c}_{1}=$ direct effect, $\mathrm{c}_{2}=$ total indirect effect, $\mathrm{c}_{3}=$ multiple mediation effect

Figure 3: Simple mediation model on job satisfaction with median split of time pressure

Figure 4: Hypothesized moderated mediation model on work engagement

Figure 5: Interaction between commitment to display rules and compassion eliciting work events for display of compassion and sympathy 
Affective Work Events and Emotions amongst Undertakers

This is a preprint of a manuscript submitted to WORK

\section{Figures}

Figure 1

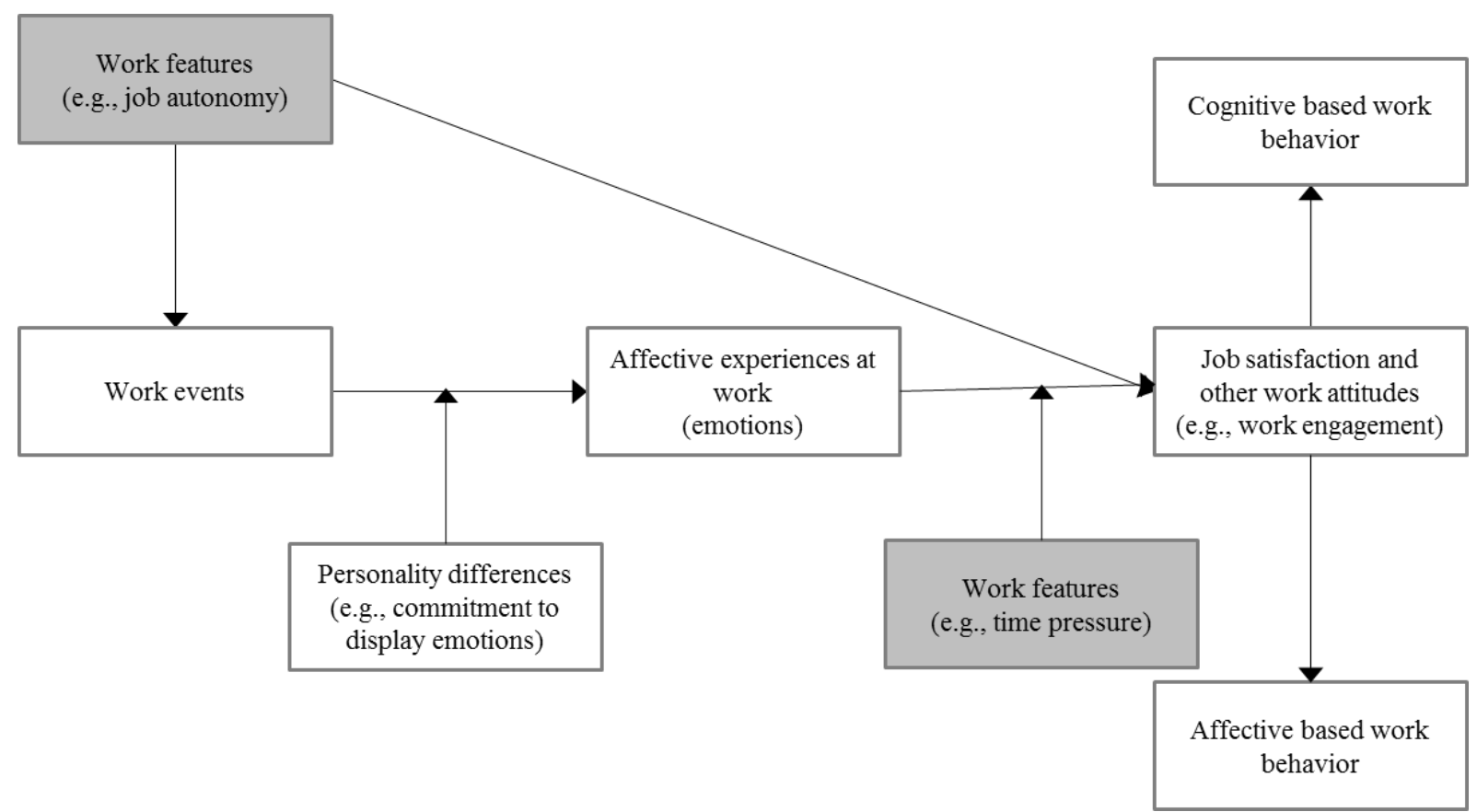

Note. The model was calculated twice with each $\mathrm{N}=52$ due to median split of time pressure. Suffix "low" refers to participants indicating lower levels of time pressure $(<\mathrm{MD})$, suffix "high" refers to participants indicating higher levels of time pressure $(>\mathrm{MD}),{ }^{*} \mathrm{p}<.05, * * \mathrm{p}<.01, \mathrm{c} 1=$ direct effect, $\mathrm{c} 2=$ indirect effect. 
Affective Work Events and Emotions amongst Undertakers

This is a preprint of a manuscript submitted to WORK

Figure 2

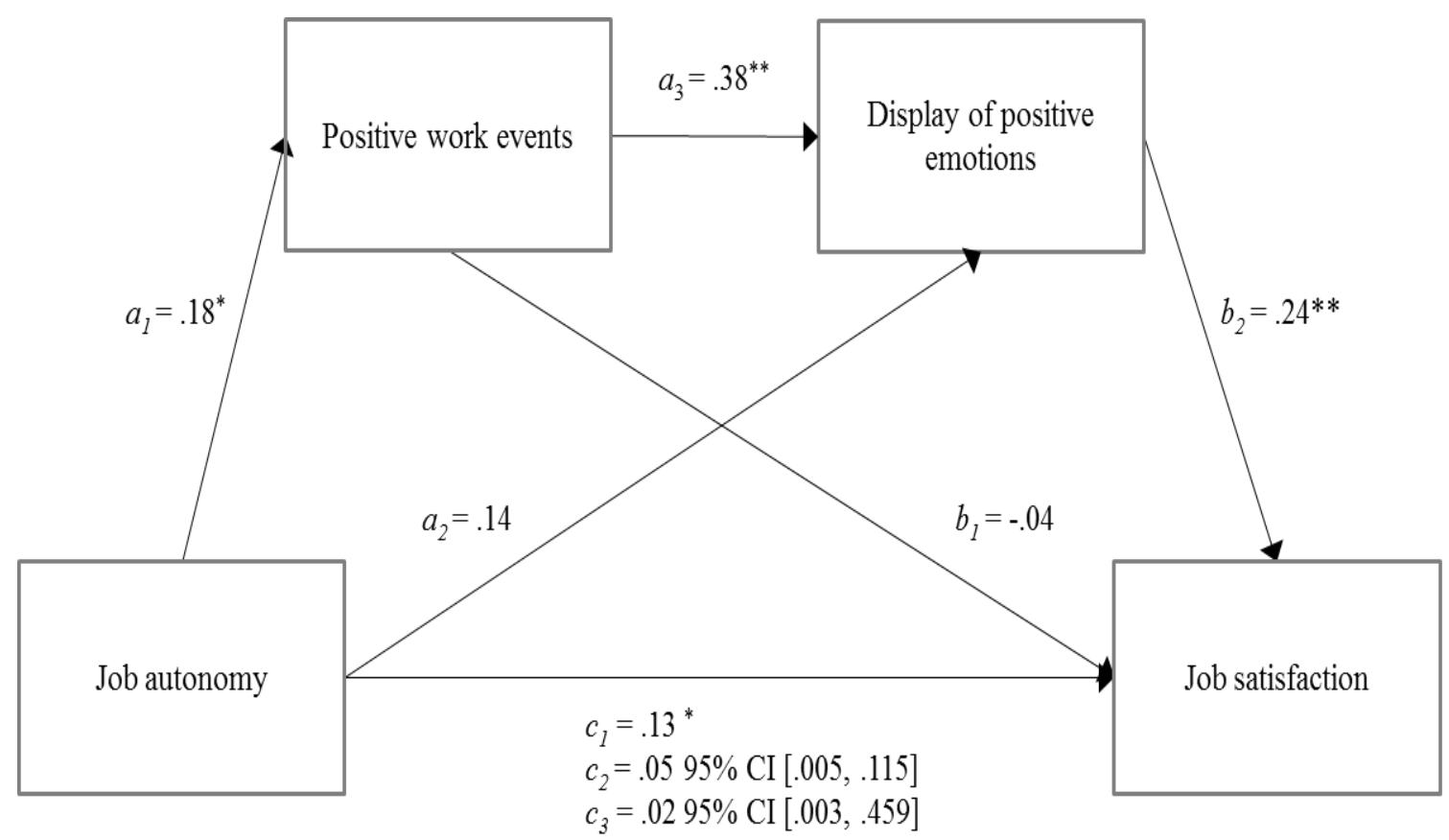


Affective Work Events and Emotions amongst Undertakers

This is a preprint of a manuscript submitted to WORK

Figure 3

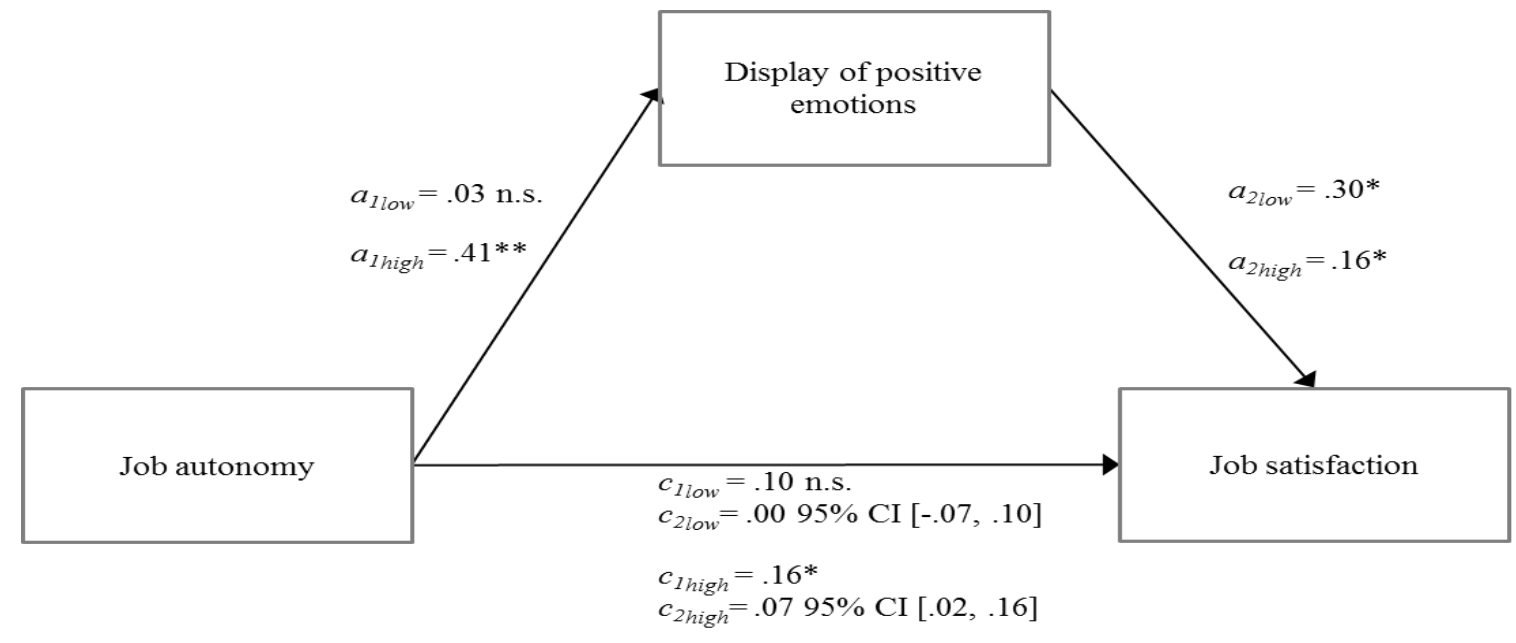


Affective Work Events and Emotions amongst Undertakers

This is a preprint of a manuscript submitted to WORK

Figure 4

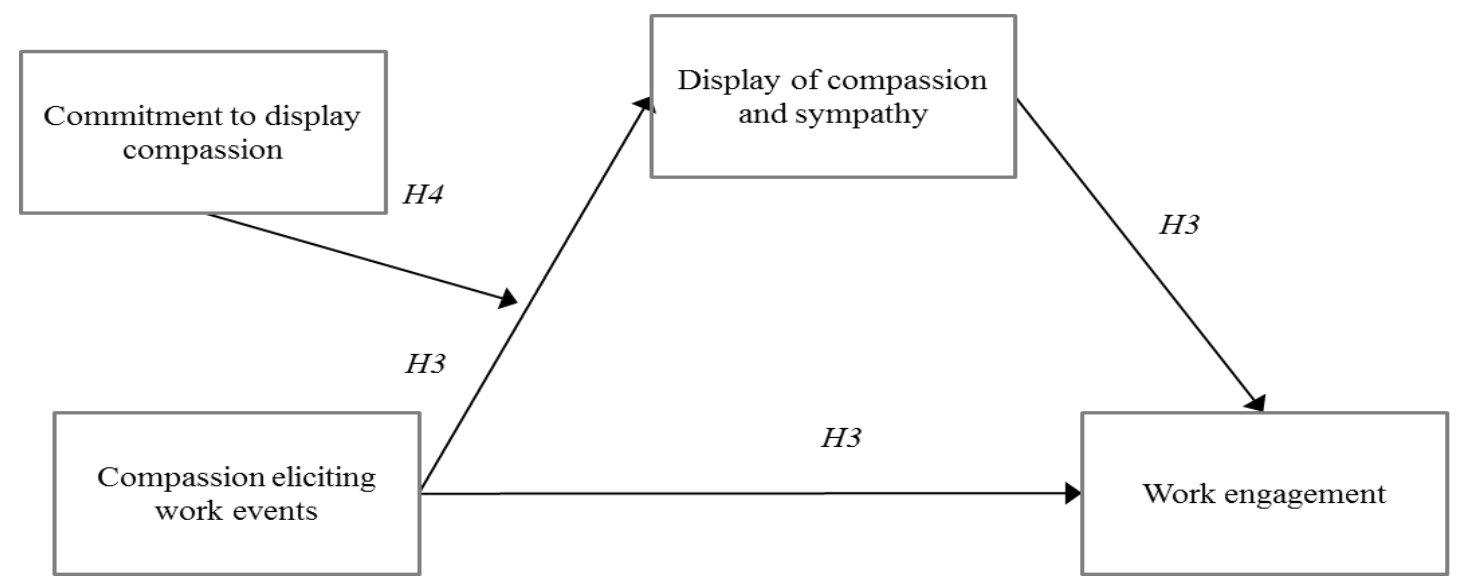


Affective Work Events and Emotions amongst Undertakers

This is a preprint of a manuscript submitted to WORK

\section{Figure 5}

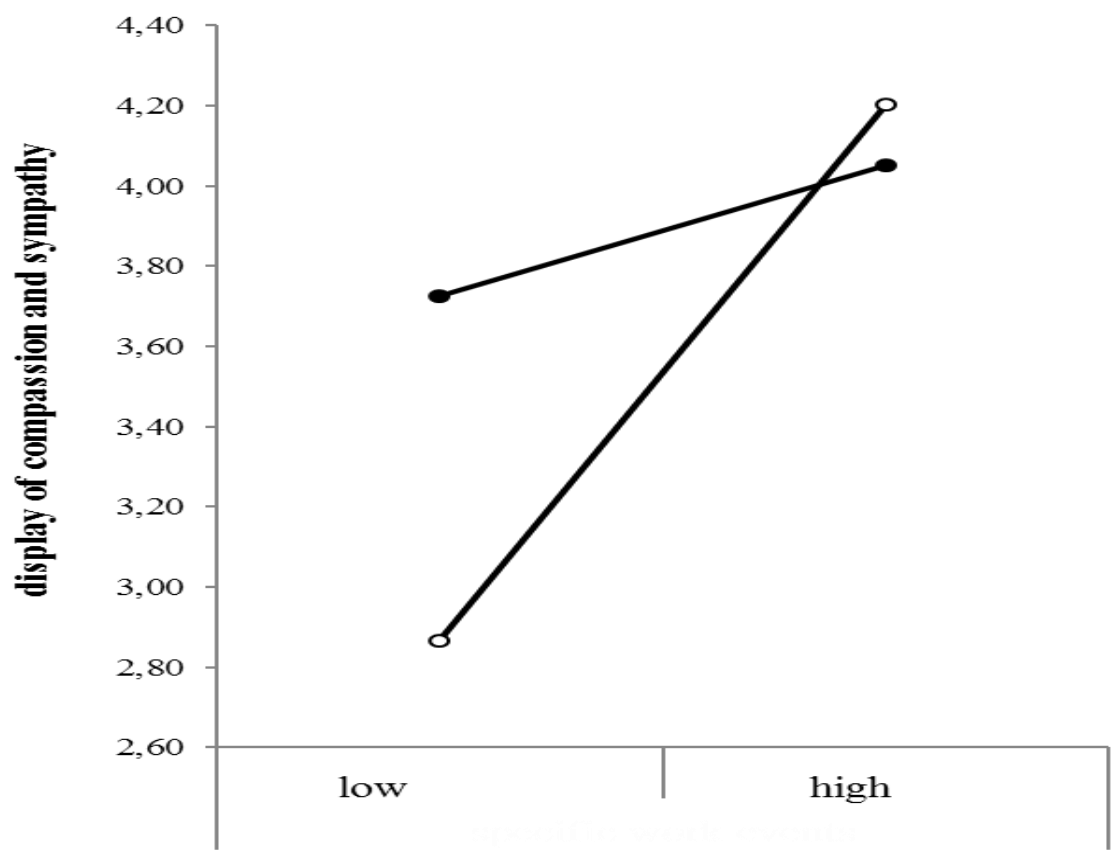

Note. $\mathrm{N}=106$ due to single missing data, $* * \mathrm{p}<.01$. low commitment to
display rules $* *$

high commitment to display rules 